\title{
Addressing Needs of Transgender Patients: The Role of Family Physicians
}

\author{
Asa E. Radix, MD, PhD, MPH
}

There are approximately 1 million transgender and gender-diverse adults in the United States. Despite increased awareness and acceptance, they frequently encounter medical settings that are not welcoming and/or health care providers who are not knowledgeable about their health needs. Use of correct terminology, following best practices for name and pronoun use, and knowledge of gender-affirming interventions can create office environments that are welcoming to transgender clients. Health disparities faced by transgender patients that impact access to care include higher rates of mental health issues, substance use disorders, violence, and poverty. Transgender women are at greater risk for HIV acquisition and are less likely to achieve viral suppression compared with cisgender (nontransgender) individuals. Medical providers can facilitate HIV prevention efforts by offering pre- and postexposure prophylaxis to transgender patients at risk for HIV infection. Improving health outcomes requires attention to cultural competency and an understanding of lived experiences and priorities of transgender people. (J Am Board Fam Med 2020;33:314-321.)

Keywords: Access to Health Care, Cultural Competency, Gender Identity, Health Personnel, HIV Infections, Sexual and Gender Minorities, Mental Health, Substance-Related Disorders, Transgender Persons, Violence

Transgender adults (i.e., those whose gender identity does not align with their sex assigned at birth) account for approximately 1 million people in the United States, or about $0.4 \%$ of the US population. ${ }^{1}$ A medical provider with a panel size of 2500 could therefore provide care to an average of 10 transgender patients. There has been increased awareness and acceptance of transgender individuals over the last decade. ${ }^{2}$ The American Academy of Family Physicians (AAFP) was one of the first medical organizations to issue curriculum guidelines outlining the skills and competencies needed to work effectively with transgender patients ${ }^{3}$ as well as to include gender identity in its patient nondiscrimination statement. ${ }^{4}$ These guidelines, first published in 2013 and last revised in 2016, list the competencies, attitudes and behaviors, knowledge,

This article was externally peer reviewed.

Submitted 7 August 2018; revised 15 October 2019; accepted 17 October 2019.

From the Callen-Lorde Community Health Center, 356 West 18th Street, New York, NY.

Funding: None

Conflicts of interest: None

Corresponding author: Asa E. Radix, MD, PhD, MPH, Callen-Lorde Community Health Center, New York, NY 10011 (E-mail: aradix@callen-lorde.org). and skills in lesbian, gay, bisexual, transgender (LGBT) health that family medicine residents optimally need to provide appropriate and high-quality care to LGBT patients. Since this health curriculum has only recently been introduced, it is unlikely that many physicians have achieved a high level of competence. There is limited research assessing knowledge of transgender health among family medicine residents; however, a recent study survey among University of Toronto residents in family medicine, psychiatry, endocrinology, and urology revealed that $51 \%$ of family medicine residents had no content in transgender health during their residency program, 53\% had no encounters with transgender people, and only $10 \%$ agreed that they would be competent in this area at the end of their training. A positive finding from this study was that more than half of the residents were interested in incorporating transgender health into their practice. ${ }^{5}$

The aim of this article is to highlight ways that family physicians can incorporate the AAFP recommendations into their clinical practice, such as understanding some of the key health issues affecting transgender people, best practices for creating welcoming settings, the basics of hormone therapies, 
and appropriately assessing individual risk for HIV and implementing appropriate prevention strategies.

\section{Terminology}

The terminology used to describe and define transgender people is constantly evolving, reflecting social and cultural trends and a clearer understanding of the diversity of gender identity and expression within the transgender community. ${ }^{6}$ Transgender women and transfeminine individuals include those who were assigned male at birth and who identify as women, transgender women, or as being on the feminine spectrum. Transgender men and transmasculine individuals include those who were assigned female at birth and identify as men, transgender men, or on the masculine spectrum. Approximately one third of transgender individuals identify as neither male or female, as both genders, or another gender; and use terms such as nonbinary, gender nonconforming, gender diverse, agender, or genderqueer. ${ }^{7,8}$

\section{Creating a Transgender-Affirming and Welcoming Environment}

Transgender individuals often avoid seeking medical care due to concerns about mistreatment in health settings. ${ }^{7}$ Family physicians have an opportunity to improve transgender patients' health care experiences by creating a welcoming environment. The 2 key principles of care are 1) respect for peoples' identities and experiences, and 2) avoiding assumptions concerning gender and gender conformity in clinical interactions.

All staff members need to be trained in how to provide care that is welcoming and respectful. The first encounter in a new medical setting can be extremely uncomfortable for a transgender person when incorrect assumptions are made about their gender. Many transgender people use chosen names that differ from their legal name or may use pronouns that differ from the gender on legal documentation. It is often at the front desk in a clinic that a perceived mismatch between a patient's gender expression and their legal name or gender marker is recognized; how the front desk staff address this discrepancy sets the tone for the patient's experience at the clinic. One example of how front desk staff can address patients when these situations arise includes "do you use a name that is different from the one on this insurance/ID card?" Another recommended practice is to gather information at the time of registration about all patients that includes their gender identity, sex assigned at birth, and pronoun usage. ${ }^{9,10}$ When pronouns are not known, staff can use the pronoun, "they." Another tip is to avoid gendered language such as "sir" and "ma'am" until you are certain of a patient's pronoun use. If a mistake is made, for example, using the wrong name or pronoun, an acknowledgment of the error and apology is the best course of action.

The National Academy of Medicine (formerly called the Institute of Medicine), Joint Commission, and other entities advise collecting information on sexual orientation and gender identity from all patients. ${ }^{11,12}$ The recommended way to collect information on gender identity is to use a 2-step ques$\operatorname{tion}^{10}$ that asks patients for both their gender identity as well as their sex assigned at birth, as some people whose gender identity is not congruent with their assigned sex at birth do not identify as transgender (Table 1). These questions have been found to be understood and acceptable to transgender individuals as well as to the majority of heterosexual, cisgender patients. ${ }^{13}$ Sexual and gender minority patients may prefer to disclose their gender identity in writing, for example by completing registration forms. ${ }^{14}$ Knowledge of a person's sex assignment at birth is important for health care providers to deliver appropriate medical care, in particular for sexual and reproductive health and cancer screenings.

Creating a welcoming environment for transgender patients also includes attention to office features such as restrooms. If these cannot be single occupancy or all gender then offices can instead have a clearly posted policy that directs patients to use the restroom that matches their gender identity. Adding images of transgender people to educational materials and displaying posters or pictures of transgender people will also demonstrate that the health facility seeks to be inclusive of gender diversity. ${ }^{16,17}$ Examples of free posters and educational materials can be found on the US Centers for Disease Control and Prevention's (CDC) Act Against AIDS initiative Web site. ${ }^{18}$ Additional items that have been suggested by community members are that clinicians improve their knowledge about transgender-specific issues such as hormone therapy and use culturally relevant language 
Table 1. Collection of Gender Identity on a Patient Registration Form ${ }^{15}$

1. What is your current gender identity? (Check and/or circle
ALL that apply)
$\square$ Male
$\square$ Female
$\square$ Transgender male/Trans man
$\square$ Transgender female/Trans woman
$\square$ Genderqueer/Gender nonconforming
$\square$ Additional identity (fill in) __
$\square$ Decline to answer
2. What sex were you assigned at birth? (Check one)
$\square$ Male
$\square$ Female
$\square$ Decline to state

when discussing identity and obtaining a sexual history. ${ }^{19}$

\section{Access to Gender-Affirming Interventions}

Transition refers to the period of time when a person starts to live in their true gender. It can include social transition (e.g., telling friends, family, and coworkers about one's gender identity and expressing one's gender identity in social contexts), legal transition (e.g., changing gender markers on legal documents) and medical transition (e.g., taking hormonal treatments and/or undergoing surgeries). Some transgender patients may request medical interventions to help align their gender presentation and/or sex characteristics with their gender identity. Family physicians can develop or improve their knowledge about medical and surgical interventions and gain expertise in hormonal therapy by following established clinical guidelines from the World Professional Association for Transgender Health, ${ }^{20}$ the Endocrine Society, ${ }^{2}$ and the University of California-San Francisco Center of Excellence for Transgender Health Primary Care Protocols $^{21}$ (Table 2).

It is important to recognize that transgender people may be at any stage of the medical gender affirmation process when seeking care. Some individuals may never plan to use hormones or undergo surgeries, while others may be seeking care specifically to access these interventions. Some may use hormonal therapy but have not had surgery, and still others may have undergone 1 or more genderaffirming procedures. Understanding which medical interventions a person has received and which interventions they are considering in the future is important to providing appropriate medical and preventive care services. For transfeminine people, hormonal therapy usually consists of estradiol and antiandrogens, such as spironolactone. This feminizing therapy results in breast growth, softening of the skin, and changes in fat distribution, resulting in a more feminine appearance. ${ }^{22}$ Transfeminine individuals may undergo several gender-affirming surgeries, including breast augmentation, chondrolaryngoplasty (tracheal shave), facial feminization surgery, orchiectomy, and vaginoplasty. ${ }^{20}$ In vaginoplasty procedures the neovagina is usually created using penile and scrotal skin but may use an intestinal or split skin graft. ${ }^{23}$ For transmasculine individuals, hormone therapy usually consists of testosterone causing deepening of the voice, increase in muscle mass and facial hair. ${ }^{24}$ Gender-affirming surgeries include bilateral mastectomy (top surgery), hysterectomy, oophorectomy, and creation of a neophallus using skin flaps from the forearm, chest wall, or thigh (phalloplasty), or a procedure that lengthens and frees the clitoris (metoidioplasty). These genital surgeries may also include scrotoplasty and testicular implants. The phalloplasty is performed in several stages, including placement of penile implants. ${ }^{23,25}$ Although many transmasculine patients will undergo hysterectomy, oophorectomy, and vaginectomy (removal of the vagina) before undergoing genital reconstruction, some will opt to keep their organs, including the vagina. Understanding the types of surgeries that patients have undergone as well as the organs that remain will help the medical provider to ascertain the need for appropriate health screenings (Table 3).

Gender-affirming hormone therapy has many positive effects, including improved mental health, psychosocial outcomes, and quality of life. ${ }^{26,27}$ These interventions, however, may also have untoward effects. Estrogen therapy in transgender women has been associated with elevated risks of

Table 2. Transgender Medicine Clinical Guidelines

World Professional Association for Transgender Health (WPATH) www.wpath.org

University of California at San Francisco Center of Excellence for Transgender Health www.transhealth.ucsf. edu

Endocrine Treatment of Gender-Dysphoric/GenderIncongruent Persons: An Endocrine Society Clinical Practice Guideline: https://academic.oup.com/jcem/article/ $102 / 11 / 3869 / 4157558$ 


\begin{tabular}{|c|c|}
\hline Masculinizing SURGERIES & Feminizing SURGERIES \\
\hline $\begin{array}{l}\text { Bilateral mastectomy: removal of both breasts, usually with nipple } \\
\text { grafts }\end{array}$ & $\begin{array}{l}\text { Breast augmentation: surgery usually requires insertion of } \\
\text { silicone or saline breast implants }\end{array}$ \\
\hline $\begin{array}{l}\text { Masculinization laryngoplasty: vocal cord surgery that augments } \\
\text { the vocal fold contours to deepen the voice }\end{array}$ & $\begin{array}{l}\text { Feminization laryngoplasty: vocal cord surgery that reduces the } \\
\text { larynx and shortens the length of the vibratory vocal fold } \\
\text { resulting in higher pitch }\end{array}$ \\
\hline $\begin{array}{l}\text { Facial masculinization surgery: this may include forehead } \\
\text { lengthening, jaw augmentation and genioplasty (chin reshaping) }\end{array}$ & $\begin{array}{l}\text { Facial feminization surgery: can include rhinoplasty, jaw } \\
\text { reduction, cheek augmentation and brow lift }\end{array}$ \\
\hline $\begin{array}{l}\text { Thyroid cartilage enhancement: surgical augmentation of the size } \\
\text { of the laryngeal prominence using rib cartilage or an implant }\end{array}$ & $\begin{array}{l}\text { Chondrolaryngoplasty: tracheal shave, reduces the size of the } \\
\text { laryngeal prominence }\end{array}$ \\
\hline Hysterectomy/oophorectomy: removal of uterus and ovaries & Orchiectomy: removal of the testicles \\
\hline $\begin{array}{l}\text { Vaginectomy: removal of the vaginal epithelium and obliteration } \\
\text { of the vaginal canal. This is done after hysterectomy. }\end{array}$ & $\begin{array}{l}\text { Vaginoplasty: creation of a vagina using penile and scrotal skin } \\
\text { or intestinal graft }\end{array}$ \\
\hline \multicolumn{2}{|l|}{ Metoidioplasty: creation of a neophallus from the clitoris } \\
\hline \multicolumn{2}{|l|}{ Phalloplasty: use of a free flap to create a neophallus } \\
\hline $\begin{array}{l}\text { Scrotoplasty: creation of a scrotum using the labia majora with } \\
\text { placement of testicular implants }\end{array}$ & \\
\hline
\end{tabular}

thromboembolic disease ${ }^{28}$ and dyslipidemia (elevated triglycerides). ${ }^{29,30}$ Transgender women may also be at increased risk for osteoporosis, especially if there is inadequate estrogen treatment after gonadectomy. ${ }^{22}$ Testosterone carries a risk of erythrocytosis, acne, vaginal atrophy, amenorrhea, and androgenetic hair loss. ${ }^{15,24}$ Since testosterone does not provide adequate protection against pregnancy, transgender men may also need counseling about effective contraception. ${ }^{15}$ Both estrogen and testosterone can negatively impact fertility in transgender people and current recommendations are to discuss fertility preservation options, such as semen, oocyte, or embryo cryopreservation before initiation of hormones, and again if patients opt to undergo gonadectomy procedures. ${ }^{31}$

\section{Health Disparities for Transgender People}

Transgender people face significant health disparities, mainly related to stigma and discrimination, as well as unique barriers to health care. ${ }^{8,12}$ A large US-based survey revealed that about 1 in 3 transgender people had a negative health care experience in the past year related to their gender identity and approximately 1 in 4 avoided care due to concerns about mistreatment in health settings. ${ }^{7}$ Transgender people frequently encounter medical professionals who lack expertise in gender-affirming care. Even when they find health care providers who are able to provide quality care, they may face additional barriers, such as health insurance plans that exclude gender-affirming medical care or surgeries. ${ }^{7}$ Several studies indicate that transgender people may be less likely to use preventive care services, such as cervical and colon cancer screening. ${ }^{32,33}$ In some cases transgender people face may face denial of coverage for preventive care services when a gender mismatch is perceived (e.g., cervical cytology for a transgender man).

Compared with the general population, transgender people, especially transgender women of color, face significant psychosocial disparities, including higher rates of homelessness, unemployment, and poverty. ${ }^{7,34}$ Many have experienced physical violence as well as school and workplace harassment. ${ }^{7}$ It is no surprise that transgender individuals have higher rates of mental health issues (anxiety and depression), substance use disorders, and violence as a consequence of these factors. ${ }^{7,35}$

\section{Primary Care}

Transgender patients who have not undergone gender-affirming care (hormones or surgeries) can use the preventive care recommendations suitable for their assigned birth sex. Although there have not been well-conducted, long-term studies that demonstrate an increase in breast cancer incidence, the Endocrine Society and the University of California at San Francisco (UCSF) primary care guidelines recommend that transgender women who have received estrogen therapy and have developed breasts be offered mammography following the guidelines for cisgender women. ${ }^{15,24}$ Transgender men who have a 
cervix need to be screened for cervical cancer, following the recommendations for cisgender women. Transgender men who have been on testosterone for more than 6 months have an increased risk of unsatisfactory Papanicolaou results, possibly due to testosterone induce atrophy. ${ }^{36}$ Cervical cancer screening using self-collected swabs for human papillomavirus testing has been found to be feasible and acceptable and may be an option for those who are reluctant to undergo examination and collection by a medical provider. ${ }^{37}$ Transgender men who have had bilateral mastectomy have been found to be at lower risk for breast cancer; however, cases do occur. ${ }^{38-40}$ Current guidelines for transgender men recommend chest-wall exams after mastectomy as well as a discussion of the risks and benefits of mammography. ${ }^{15,41}$ Transgender men who have the capacity for pregnancy, that is, have a uterus and ovaries, can get pregnant while on testosterone ${ }^{42}$ and may therefore need counseling about fertility and contraceptive options. ${ }^{43}$ There are no standard guidelines addressing when to start screening for osteoporosis in transgender women; however, 1 author suggests starting after age 40 years if risk factors are present. ${ }^{22}$

\section{HIV}

Transgender patients experience many health disparities but possibly the most concerning is the high rate of HIV infection. Transgender women in the United States have an estimated HIV prevalence of $14 \%$, one of the highest prevalence rates of any group, except for men who have sex with men (MSM). ${ }^{44,45}$ African-American transgender women face an even greater disparity in HIV prevalence, with up to $44.2 \%$ living with HIV compared with $25.8 \%$ of Hispanic/Latina transgender women and $6.7 \%$ of white transgender women. ${ }^{45}$ Although transgender men have a lower HIV prevalence rate $(3.2 \%)$, those who identify as gay and have sex with cis-gender MSM may be at higher risk for HIV infection. ${ }^{45,46}$ Once diagnosed with HIV, transgender women continue to face further disparities lower rates of viral suppression compared with cisgender people. ${ }^{47,48}$ This may be due to having increased risk factors associated with nonadherence to antiretroviral therapy, such as poverty, housing instability, physical and emotional trauma, ${ }^{49,50}$ prioritization of other health issues, ${ }^{51}$ or concern about the potential for drug inter- actions between their hormone therapy and antiretroviral agents. ${ }^{52,53}$

Medical providers can also help to diminish some of the HIV-related health disparities that transgender people face. This starts with assessing risk for HIV and sexually transmitted diseases. When obtaining a sexual health history from transgender patients, providers can continue to follow the strategies of showing respect and avoiding assumptions, especially regarding sexual behaviors and the gender of sexual partners. Providers need to be sensitive to the fact that transgender people may prefer other words to describe their bodies. For example, a transgender man may use "chest" rather than "breast," regardless of whether he has had "top surgery" (ie, a mastectomy or breast reduction surgery). Providers can ask patients about their preferred terms for body parts or use less gendered language (e.g., use "genitals" instead of "penis" or "vagina"). ${ }^{54}$ Using gender neutral terms is preferred by some clinicians as it can be challenging to remember the terms used by every patient. If patients engage in receptive anal or oral sex, these sites are screened with a rectal swab for gonorrhea and chlamydia and an oral swab for gonorrhea, per CDC guidelines. ${ }^{55}$ The preferred method uses nucleic acid amplification testing. Currently there is no guideline regarding routine screening of the surgically constructed neovagina; however, testing is recommended if the patient is symptomatic.

Both the CDC and the US Preventive Services Task Force recommend that adolescents and adults receive at least a 1-time screening for HIV screening. ${ }^{56,57}$ This is especially important for people of transgender experience given their elevated HIV risk. ${ }^{58}$

Counseling about risk reduction includes discussions about HIV pre-exposure prophylaxis (PrEP) and postexposure prophylaxis. Studies indicate that knowledge about PrEP is low among transgender women. ${ }^{30}$ Additional barriers to PrEP for transgender women include medical mistrust, concerns about drug-drug interactions with hormone therapy, financial or insurance barriers and lack of representation in educational materials. ${ }^{31}$ Data on the efficacy of PrEP-specifically tenofovir disoproxil fumarateemtricitabine-among transgender women are limited. A recent subanalysis of the Pre-Exposure Prophylaxis Initiative (iPrEx) trial revealed that PrEP adherence was lower among transgender women than MSM. In addition, PrEP efficacy among transgender women was not demonstrated; 
however, no transgender woman who seroconverted was taking PrEP as prescribed. ${ }^{32}$ This underscores the importance of facilitating PrEP adherence among transgender women. Clinicians can improve awareness about PrEP among transgender patients, reassure their patients about the lack of significant interactions between hormone therapy and tenofovir disoproxil fumarate-emtricitabine used for PrEP, and direct patients to assistance programs to reduce outof-pocket costs (https://preplocator.org/). Medical providers can find educational materials that feature transgender people at the CDC's Act Against AIDS Web site. ${ }^{18}$

As with all people living with HIV, transgender individuals will have better health outcomes if they are engaged in care and are able to achieve viral suppression through optimal adherence to antiretroviral therapy. Transgender-friendly support services and other services important to transgender people, including case management, legal assistance, and housing referrals can be offered if needed. Lastly, patients need to be reassured about the safety of using both hormones and antiretroviral therapy. Many antiretroviral regimens have no interactions with estrogens. ${ }^{35}$ Although interactions may occur with boosted protease inhibitors, resulting in lower estrogen levels, careful monitoring and dose adjustments allow providers to both successfully treat HIV and enable optimal use of hormonal therapy. ${ }^{59}$

The AAFP's comprehensive curriculum on LGBT health outlines attitudes, knowledge and skills that are critical for delivery of appropriate care to sexual and gender minority people. Family physicians who implement these recommendations into clinical practice will help to drive improved health outcomes for transgender patients. Clinicians need to be aware of the barriers to effective HIV prevention and treatment in transgender communities and use existing resources to improve HIV screening, provision of $\mathrm{PrEP}$ and postexposure prophylaxis and linkage to HIV treatment services. Ensuring a gender-affirming clinical environment and gaining clinical expertise in transgender medicine are the cornerstones to achieving these goals.

To see this article online, please go to: http://jabfm.org/content/ 33/2/314.full.

\section{References}

1. Meerwijk EL, Sevelius JM. Transgender population size in the United States: a meta-regression of population-based probability samples. Am J Public Health 2017;107:216.

2. Hembree WC, Cohen-Kettenis P, Delemarre-van de Waal HA, et al. Endocrine treatment of transsexual persons: an Endocrine Society clinical practice guideline. J Clin Endocrinol Metab 2009; 94:3132-3154.

3. American Academy of Family Physicians. Recommended curriculum guidelines for family medicine residents lesbian, gay, bisexual, transgender health. In: AAFP, ed. AAFP Reprint No. 289D. August 2016.

4. American Academy of Family Physicians. American Academy of Family Physicians, AAFP policy statements: discrimination, patient (1996, 2010 COD). 2010.

5. Coutin A, Wright S, Li C, Fung R. Missed opportunities: are residents prepared to care for transgender patients? A study of family medicine, psychiatry, endocrinology, and urology residents. Can Med Ed J 2018;9:e41-e55.

6. Schwend AS, Motmans J, Smiley A, et al Language and trans health AU-Bouman, Walter Pierre. Int J Transgenderism 2017;18:1-6.

7. James SE, Herman JL, Rankin S, Keisling M, Mottet L, Anafi M. The report of the 2015 U.S. Transgender Survey, Washington, DC: National Center for Transgender Equality; 2016.

8. Liszewski W, Peebles JK, Yeung H, Arron S. Persons of nonbinary gender-Awareness, visibility, and health disparities. N Engl J Med 2018;379: 2391-2393.

9. Reisner SL, Radix A, Deutsch MB. Integrated and gender-affirming transgender clinical care and research. JAIDS 2016;72:S235-242.

10. Cahill S, Singal R, Grasso C, et al. Do ask, do tell: high levels of acceptability by patients of routine collection of sexual orientation and gender identity data in four diverse American community health centers. PLoS ONE 2014;9:e107104.

11. Advancing effective communication, cultural competence, and patient- and family-centered care for the lesbian, gay, bisexual, and transgender (lgbt) community: a field guide. In: Commission TJ, ed. Oak Brook, IL: The Joint Commision; 2011.

12. Institute of Medicine; Board on the Health of Select Populations; Committee on Lesbian, Gay, Bisexual, and Transgender Health Issues and Research Gaps and Opportunities. The health of lesbian, gay, bisexual, and transgender people: building a foundation for better understanding. Washington, DC: National Academies Press; 2011.

13. Rullo JE, Foxen JL, Griffin JM, et al. Patient acceptance of sexual orientation and gender identity questions on intake forms in outpatient clinics: a pragmatic randomized multisite trial. Health Serv Res 2018;53:3790-3808.

14. Haider A, Adler RR, Schneider E, et al. Assessment of patient-centered approaches to collect sexual orientation and gender identity information in the 
emergency department: the EQUALITY study. JAMA Netw Open 2018;1:e186506.

15. Center of Excellence for Transgender Health DoFaCM, University of California San Francisco. Guidelines for the primary and gender-affirming care of transgender and gender nonbinary people. In: Deutsch M, ed. 2nd ed, San Francisco, CA; University of California San Francisco, 2016. Available from: www.transhealth.ucsf.edu/. Accessed December 20, 2018.

16. Croghan CF, Moone RP, Olson AM. Working with LGBT baby boomers and older adults: factors that signal a welcoming service environment. J Gerontologic Soc Work 2015;58:637-651.

17. Kano M, Silva-Banuelos AR, Sturm R, Willging CE. Stakeholders' recommendations to improve patient-centered "LGBTQ" primary care in rural and multicultural practices. J Am Board Fam Med 2016;29:156-160.

18. Prevention CfDCa. Act Against AIDS. Available from: https://www.cdc.gov/actagainstaids/.

19. Willging CE, Salvador M, Kano M. Brief reports: unequal treatment: mental health care for sexual and gender minority groups in a rural state. Psych Serv 2006;57:867-870.

20. Coleman E, Bockting $W$, Botzer $M$, et al. Standards of care for the health of transsexual, transgender, and gender-nonconforming people, version 7. Int J Transgender 2012;13:165-232.

21. Center of Excellence for Transgender Health. Primary care protocol for transgender patient care. 2011. Available from: http://transhealth.ucsf.edu/ trans? page $=$ protocol-00-00.

22. Tangpricha $\mathrm{V}$, den Heijer M. Oestrogen and antiandrogen therapy for transgender women. Lancet Diabetes Endocrinol 2017;5:291-300.

23. Schechter LS. Gender confirmation surgery: an update for the primary care provider. Transgender Health 2016;1:32-40.

24. Hembree WC, Cohen-Kettenis PT, Gooren L, et al. Endocrine treatment of gender-dysphoric/ gender-incongruent persons: an Endocrine Society* clinical practice guideline. J Clin Endocrinol Metab 2017;102:3869-3903.

25. Schechter LS, Safa B. Introduction to phalloplasty. Clinics Plastic Surg 2018;45:387-389.

26. de Vries AL, McGuire JK, Steensma TD, Wagenaar EC, Doreleijers TA, Cohen-Kettenis PT. Young adult psychological outcome after puberty suppression and gender reassignment. Pediatrics 2014;134: 696-704.

27. White Hughto JM, Reisner SL. A systematic review of the effects of hormone therapy on psychological functioning and quality of life in transgender individuals. Transgender Health 2016;1:21-31.

28. Getahun D, Nash R, Flanders WD, et al. Cross-sex hormones and acute cardiovascular events in transgender persons: a cohort study. Ann Intern Med 2018;169:205-213.

29. Elbers JMH, Giltay EJ, Teerlink T, et al. Effects of sex steroids on components of the insulin resistance syndrome in transsexual subjects. Clin Endocrinol 2003;58:562-571.

30. Maraka S, Singh Ospina N, Rodriguez-Gutierrez $\mathrm{R}$, et al. Sex steroids and cardiovascular outcomes in transgender individuals: a systematic review and meta-analysis. J Clin Endocrinol Metab 2017;102: 3914-3923.

31. Mattawanon N, Spencer JB, Schirmer DA 3rd, Tangpricha V. Fertility preservation options in transgender people: A review. Rev Endocr Metab Disord 2018;19:231-242.

32. Peitzmeier SM, Khullar K, Reisner SL, Potter J. Pap test use is lower among female-to-male patients than non-transgender women. Am J Prevent Med 2014;47:808-812.

33. Tabaac AR, Sutter ME, Wall CSJ, Baker KE. Gender identity disparities in cancer screening behaviors. Am J Prevent Med 2018;54:385393.

34. Bradford J, Reisner SL, Honnold JA, Xavier J. Experiences of transgender-related discrimination and implications for health: results from the Virginia Transgender Health Initiative Study. Am J Public Health 2013;103:1820-1829.

35. Herbst JH, Jacobs ED, Finlayson TJ, et al. Estimating HIV prevalence and risk behaviors of transgender persons in the United States: a systematic review. AIDS Behav 2008;12:1-17.

36. Peitzmeier SM, Reisner SL, Harigopal P, Potter J. Female-to-male patients have high prevalence of unsatisfactory Paps compared to non-transgender females: implications for cervical cancer screening. J Gen Intern Med 2014;29:778-784.

37. Reisner SL, Deutsch MB, Peitzmeier SM, et al. Test performance and acceptability of self- versus provider-collected swabs for high-risk HPV DNA testing in female-to-male trans masculine patients. PLoS ONE 2018;13:e0190172.

38. Ganly I, Taylor EW. Breast cancer in a trans-sexual man receiving hormone replacement therapy. $\mathrm{Br} \mathrm{J}$ Surg 1995;82:341-341.

39. Burcombe RJ, Makris A, Pittam M, Finer N. Breast cancer after bilateral subcutaneous mastectomy in a female-to-male trans-sexual. The Breast 2003;12: 290-293.

40. Nikolic DV, Djordjevic ML, Granic M, et al. Importance of revealing a rare case of breast cancer in a female to male transsexual after bilateral mastectomy. World J Surg Onc 2012;10:280-280.

41. Deutsch MB, Radix A, Wesp L. Breast cancer screening, management, and a review of case study literature in transgender populations. Semin Reprod Med 2017;35:434-441.

42. Light AD, Obedin-Maliver J, Sevelius JM, Kerns JL. Transgender men who experienced pregnancy 
after female-to-male gender transitioning. Obstet Gynecol 2014;124:1120-1127.

43. Light A, Wang LF, Zeymo A, Gomez-Lobo V. Family planning and contraception use in transgender men. Contraception 2018;98:266-269.

44. Baral SD, Poteat T, Stromdahl S, Wirtz AL, Guadamuz TE, Beyrer C. Worldwide burden of $\mathrm{HIV}$ in transgender women: a systematic review and meta-analysis. Lancet Infect Dis 2013;13:214222.

45. Becasen JS, Denard CL, Mullins MM, Higa DH, Sipe TA. Estimating the prevalence of HIV and sexual behaviors among the US transgender population: a systematic review and meta-analysis, 20062017. Am J Public Health 2018;e1-e8.

46. Reisner SL, Murchison GR. A global research synthesis of HIV and STI biobehavioural risks in female-to-male transgender adults. Global Pub Health 2016;11:866-887.

47. Mizuno Y, Frazier EL, Huang P, Skarbinski J. Characteristics of transgender women living with $\mathrm{HIV}$ receiving medical care in the United States. LGBT Health 2015;2:228-234.

48. Doshi RK, Milberg J, Jumento T, Matthews T, Dempsey A, Cheever LW. For many served by the Ryan White HIV/AIDS program, disparities in viral suppression decreased, 2010-14. Health Aff (Project Hope) 2017;36:116-123.

49. Grant JM, Mottet LA, Tanis J. National transgender discrimination survey report on health and health care. Washington, DC: National Center for Transgender Equality and the National Gay and Lesbian Task Force; 2010.

50. Machtinger EL, Haberer JE, Wilson TC, Weiss DS. Recent trauma is associated with antiretroviral failure and HIV transmission risk behavior among HIV-positive women and female-identified transgenders. AIDS Behav 2012;16:2160-2170.

51. Sevelius JM, Patouhas E, Keatley JG, Johnson MO. Barriers and facilitators to engagement and reten- tion in care among transgender women living with human immunodeficiency virus. Ann Behav Med 2013;47:5-16.

52. Sevelius JM, Carrico A, Johnson MO. Antiretroviral therapy adherence among transgender women living with HIV. J Assoc Nurses AIDS Care 2010;21:256264.

53. Braun HM, Candelario J, Hanlon CL, et al. Transgender women living with HIV frequently take antiretroviral therapy and/or feminizing hormone therapy differently than prescribed due to drug-drug interaction concerns. LGBT Health 2017;4:371-375.

54. Potter J, Peitzmeier SM, Bernstein I, et al. Cervical cancer screening for patients on the female-to-male spectrum: a narrative review and guide for clinicians. J Gen Intern Med 2015;30:1857-1864.

55. Workowski KA, Bolan GA. Sexually transmitted diseases treatment guidelines, 2015. MMWR Recomm Rep 2015;64:1-137.

56. Moyer VA. Screening for HIV: U.S. Preventive Services Task Force Recommendation Statement. Ann Intern Med 2013;159:51-60.

57. Branson BM, Handsfield HH, Lampe MA, et al. Revised recommendations for HIV testing of adults, adolescents, and pregnant women in healthcare settings. MMWR Recomm Rep 2006;55:1-17. Quiz CE11-14.

58. Pitasi MA, Kerani RP, Kohn R, et al. Chlamydia, gonorrhea, and human immunodeficiency virus infection among transgender women and transgender men attending clinics that provide sexually transmitted disease services in six US cities: results from the Sexually Transmitted Disease Surveillance Network. Sex Transm Dis 2019;46:112-117.

59. Panel on Antiretroviral Guidelines for Adults and Adolescents. Guidelines for the use of antiretroviral agents in HIV-1-infected adults and adolescents. Washington, DC: Department of Health and Human Services; 2018 